\title{
PENSION, FERTILITY, AND EDUCATION
}

\author{
VOLKER MEIER \\ MATTHIAS WREDE
}

CESIFO WORKING PAPER No. 1521

CAtegory 1: Public FinANCE

August 2005

An electronic version of the paper may be downloaded

- from the SSRN website:

www.SSRN.com

- from the CESifo website: www.CESifo-group.de 


\title{
PENSION, FERTILITY, AND EDUCATION
}

\begin{abstract}
A pay-as-you-go pension scheme is associated with positive externalities of having children and providing them with human capital. In a framework with heterogeneity in productivity, and stochastic and endogenous investment in fertility and education, we discuss internalization policies associated with child benefits in the pension formula. The second-best scheme displays both a benefit contingent on the contributions of children and a purely fertility-related component.
\end{abstract}

JEL Code: H23, H55, J13, J18.

Keywords: pay-as-you-go, fertility, human capital, externalities.

Volker Meier

Ifo Institute for Economic Research at the

University of Munich

Poschingerstr. 5

81679 Munich

Germany

meier@ifo.de
Matthias Wrede

Department of Economics and Business

Administration

RWTH Aachen University

Templergraben 64

52056 Aachen

Germany

mwr@fiwi.rwth-aachen.de 


\section{Introduction}

Investing in the quantity and quality of children is associated with positive fiscal externalities when a pay-as-you-go (PAYG) pension scheme is in place. In such a system, the contributions paid by workers are immediately spent on current pensioners. With given social security contribution rates, total contributions rise both with a higher number and a higher productivity of contributors. Hence, when individuals decide to have children or to provide them with human capital, utility levels of other individuals in the same generation will rise through higher expected pension claims. Consequently, people tend to invest too little in the number and quality of their children. This problem counteracts the function of a PAYG pension scheme as an enforcement device to ensure sufficiently high transfers from children to their parents (Sinn, 2004).

Our paper addresses the question of how the pension formula has to be adapted in order to incorporate the externalities in some sense of optimality. While other policy instruments such as family allowances or scholarships for talented students may serve the same purpose, it is interesting to find out the consequences if the internalization takes place only in the pension scheme. The analysis allows conclusions with respect to the use of alternative policy instruments, as equivalent instrument sets can be constructed. In our study, the goal is to maximize the sum of utilities in the parent generation given a fixed social security contribution rate on wages. We consider an economy with heterogeneity in productivity where the outcomes of investment in both fertility and education are stochastic.

In addition to the externality problem, it has been noted that the extension of public pensions drives down fertility. Public pensions crowd out transfer schemes within families. If individuals do not care about the wellbeing of their offspring, the smaller transfers old parents receive from their children reduce the demand for children (Cigno, 1993). The same prediction turns out if parents are altruistic toward their children provided that the economy is in a dynamically efficient situation, that is, when the rate of re- 
turn in a PAYG scheme falls short of the interest rate. While parents would like to compensate their children for the social security transfer, the implicit tax on contributions raises the price of a child, reducing the demand for children (Becker and Barro, 1988). Empirical evidence for the negative impact of social security on fertility is presented in Cigno and Rosati (1996), Cigno et al. (2003), and Boldrin et al. (2005). Although a similar argument can be given when considering education, it is not considered as empirically relevant. The asymmetry is a consequence of differences in policy interventions. Many countries have already adopted some type of child benefit in the pension formula, but the size of these benefits is much smaller everywhere than the contributions of the child to the pension system. At the same time, schooling is subsidized at a rate of almost one hundred per cent. In our analysis we ignore observable education and focus on human capital acquisition within the family. As lots of studies stress the importance of the family background when explaining educational outcomes (for example, Woessmann, 2004), setting incentives for unobservable education effort at home seems to be quite appropriate.

In order to keep the analysis simple, we investigate a framework of a small open economy with a stationary technology. We ignore impacts of changing parameters of the PAYG pension system on growth via savings, which have been discussed in endogenous growth settings by Zhang (1995) and Wigger (1999). Both fertility and the individual's productivity is stochastic where in each case the level of investment affects the probability distribution of outcomes. As a result, we have both high and low productive households, with and without children. Mirroring a stylized fact, we assume that the direct cost of providing a child with a given level of education is lower for high productivity parents. The heterogeneity of individuals enables us to study the impacts of financial incentives on different groups. It is not obvious how an 'optimum' mix of encouraging fertility and education should look like. Individuals first choose the level of their fertility investment. After the number of children is known, people decide on savings and human capital 
investment. Some intrinsic motivation for having children and a preference for letting them arrive at a high productivity will yield positive investment in the quantity and quality of human capital even in the absence of financial incentives. The pension consists of up to four components: a share contingent on previous earnings, a benefit that depends on the number of children, a component that assigns parts of the children's contributions to their parents, and a flat benefit. Individuals exhibit quasi-linear preferences. The obvious drawback of this specification is the exclusive impact of income changes on working age consumption. This problem may be outweighed by the advantage that utilities can simply be added in the welfare analysis, where results are not driven by distributional aspects within a generation.

With this specification, increasing fertility-related pensions will lead to a larger number of children while not affecting the educational effort levels of parents. In contrast, a higher share of children's contributions directly transferred to their parents will yield both more human capital investment and a higher number of children. The latter result is a consequence of the fact that children become more profitable for their parents.

In any first-best allocation, investment in fertility and education will be increased to the level where the marginal cost is equal to the aggregate marginal benefit arising for the parent generation. At the same time, old age consumption is perfectly smoothed across all states. The former optimality condition requires incentives for investment in education. However, using such incentives implies that consumption smoothing will not be achieved when the outcome of the investment decision is uncertain. The second-best scheme therefore displays the property that parents collect some of their children's contributions, but not the full amounts. As some underinvestment in fertility would otherwise occur, the optimum scheme is also associated with some fertility-related component.

The standard message of the literature on PAYG pensions and endogenous is that an internalization of the positive externality requires that the full PAYG pension is made contingent on fertility (Kolmar, 1997). This result 
carries over to several alternative specifications, as allowing for migration (Kolmar, 2001) or decision-making by couples (Abio et al., 2004). As an alternative, family allowances can be introduced being equal to the present value of a child's contribution (van Groezen et al., 2003; van Groezen and Meijdam, 2004). This amount represents the net social gain of an additional individual given that her pension will be financed by her children (Sinn, 2001).

In some recent papers, several arguments have been given, under which circumstances the standard proposition will fail. First, a stronger fertility incentive can reduce lifetime labor supply, imposing a negative externality on the older generation through declining pensions (Fenge and Meier, 2004 and 2005). Second, if the outcome of the fertility decision is stochastic, the optimum scheme sets milder fertility incentives in order to decrease the income risk (Cremer et al., 2004a). Third, if individuals exhibit cost differences in raising children, a utilitarian government will choose to redistribute towards high cost individuals, which again calls for less fertility-related pensions (Cremer et al., 2004b).

Few attempts have been undertaken to study the interactions of fertility, investment in human capital, and PAYG pensions. Peters (1995) analyzes a closed economy framework in which the government can subsidize private education. He finds a quantity-quality tradeoff, and argues that education will always be subsidized while fertility may be taxed. The contributions closest in spirit to our analysis are Cigno et al. (2003) and Cigno and Luporini (2003). The former discusses a framework in which parents can deterministically choose the number of children and an action that affects the child's tax-paying capacity in a stochastic fashion. While the government can force the individuals to choose the optimum number of children, transfers to parents are made contingent on the child's performance, for example by a scholarship. As in our paper, Cigno and Luporini (2003) introduce stochastic fertility and cost differences across parents in providing their children with human capital. The optimum tax-transfer scheme is associated with pay- 
ments contingent on the child's performance and a purely fertility-related component to insure parents against an unfortunate outcome of their human capital investment decision. These features appear again in our framework in which we apply quite a similar structure to the specific problem arising in the PAYG pension scheme. We depart from the analysis of Cigno and Luporini in two respects. First, we add heterogeneity in income in the parent generation that determines the private cost of educating children, which is therefore observable for the government. Second, we eliminate the government's motive for income redistribution by imposing quasi-linear preferences. Therefore, the results reflect only efficiency issues.

The remainder of the paper is organized as follows. Section 2 introduces the model. The comparative static analysis in Section 3 discusses the impacts on changing parameters in the pension formula on saving, fertility and human capital investment. Section 4 deals with the structure of first-best allocations and shows that welfare losses will necessarily arise in our imperfect information framework. In the following Section 5, second-best pension schemes are characterized. The final Section 6 discusses the main findings.

\section{The model}

We consider a small open economy where the rate of interest and the wage rate for one efficiency unit of labor is determined at the world market. In order to analyze fertility choices, we employ a three-period overlapping generations model. For simplicity, we consider a one-sex population consisting of females. A generation lives for three periods. In the first period an individual lives with her parent. She receives an education level $e$ which is chosen by her mother.

In the second period, the productivity of the individual is revealed, being either high, $\theta_{h}$, or low, $\theta_{l}$, with $\theta_{l}<\theta_{h}$. An individual of type $i \in\{h, l\}$ supplies one unit of labor and receives a gross wage income $\theta_{i}$. The wage rate for one efficiency unit of labor is normalized to one. Furthermore, the 
household of type $i$ chooses the investment $m_{i}$ that affects the expected number of children she will have in this period. ${ }^{1}$ In contrast to Cigno and Luporini (2003), the activity is associated with an expenditure which serves to avoid corner solutions in the absence of a PAYG scheme. The outcome of the fertility investment, represented by the number of children, is stochastic. With probability $p_{i}=p\left(m_{i}\right)$ the realized number of children will be $n$, with $n>0$. In the opposite event, occurring with probability $1-p_{i}$, the number of children will be zero. The fertility investment increases the probability of having children, i.e. $p_{i}^{\prime}>0$, but at a decreasing rate, $p_{i}^{\prime \prime}<0$. Raising one child is associated with a cost $K$.

Knowing the realized number of children $j$ with $j \in\{0, n\}$, a household of type $i$ decides how much to save, $s_{i j}$, and to consume, $c_{i j}$, and, provided that there are children, how much to invest in the education of each child, $\rho\left(\theta_{i}\right) e_{i}$, with $e_{i} \geq 0$. The cost of providing children with a given level of education varies according to the productivity of the mother, with $\rho^{\prime}<0$. The cost advantage of high productivity parents reflects either possible genetic factors or the home environment, as factors in human capital production explaining the observable intergenerational correlation of abilities. The outcome of the investment depends on the input in a stochastic fashion. With probability $q_{i}=q\left(e_{i}\right)$, all siblings will have high productivity $\theta_{h}$. Otherwise, with probability $1-q_{i}$, all siblings end up with productivity $\theta_{l}$. The assumption of perfect correlation across siblings is just taken for simplicity. To ensure interior solutions, the human capital production function exhibits the properties $q_{i}^{\prime}>0, q_{i}^{\prime \prime}<0, \lim _{e \rightarrow 0} q_{i}^{\prime}=\infty, \lim _{e \rightarrow \infty} q_{i}^{\prime}=0$. Finally, an adult has to pay contributions to the PAYG pension system in her working period, where the contribution rate is $\tau$. Hence, consumption in the second period is given by

$$
\begin{aligned}
& c_{i 0}=(1-\tau) \theta_{i}-s_{i 0}-m_{i}, \\
& c_{i n}=(1-\tau) \theta_{i}-s_{i n}-m_{i}-n\left(K+\rho\left(\theta_{i}\right) e_{i}\right),
\end{aligned}
$$

without and with children, respectively.

\footnotetext{
${ }^{1}$ In order to simplify notation, a superscript to indicate the period under consideration is omitted throughout the paper wherever possible.
} 
In the third period a mother of type $i$ with $n$ children of type $k$ retires and consumes $z_{i n}^{k}$. Old age consumption equals the sum of private savings multiplied by the interest factor $R$ and the pension $\pi_{i n}^{k}$ :

$$
z_{i n}^{k}=R s_{i n}+\pi_{i n}^{k}
$$

A childless retiree receives a pension $\pi_{i 0}$ and consumes $z_{i 0}=R s_{i 0}+\pi_{i 0}$.

Since our focus is not on intra-generational redistribution, but on the relationship between, on the one hand, the PAYG system and, on the other hand, fertility and education, we assume quasi-linear preferences. As a consequence, the aim to redistribute between rich and poor does not bias the results. A childless parent and a mother of type $i$ with $n$ children of type $k$ achieve utility

$$
\begin{aligned}
U_{i \mathbf{0}} & =c_{i \mathbf{0}}+v\left(z_{i 0}\right), \\
U_{i n}^{k} & =c_{i n}+v\left(z_{i n}^{k}\right)+\psi\left(\theta_{k}\right),
\end{aligned}
$$

respectively, where $v^{\prime}>0$ and $v^{\prime \prime}<0$. The function $\psi$ measures how the existence of children and the productivity of children directly increase the utility of their mother, where $0<\psi\left(\theta_{l}\right)<\psi\left(\theta_{h}\right)$. Denoting expected utility after the number of children is revealed by

$$
\left.E U_{i}\right|_{n}:=c_{i n}+q\left(e_{i}\right)\left[v\left(z_{i n}^{h}\right)+\psi\left(\theta_{h}\right)\right]+\left(1-q\left(e_{i}\right)\right)\left[v\left(z_{i n}^{l}\right)+\psi\left(\theta_{l}\right)\right],
$$

expected lifetime utility is simply

$$
E U_{i}=\left.p\left(m_{i}\right) E U_{i}\right|_{n}+\left(1-p\left(m_{i}\right)\right) U_{i \mathbf{0}}
$$

where utility in the first period, when no decision is taken, is omitted.

The state-run PAYG pension system relates pensions to previous own contributions, number of children, contributions of children, and a flat component according to the formulas

$$
\begin{aligned}
& \pi_{i 0}=\alpha \theta_{i}+\delta \\
& \pi_{i n}^{k}=\alpha \theta_{i}+\beta n+\gamma n \theta_{k}+\delta .
\end{aligned}
$$


The pension parameters are restricted by $\alpha \geq 0, \beta \geq 0,0 \leq \gamma \leq \tau$. If $\gamma$ were larger than $\tau$, total benefits based on own childrens' contributions would exceed total contributions to a PAYG scheme. Neglecting the budget restriction of the PAYG scheme, all parameters affect pensions non-negatively.

Each adult solves a two-stage decision problem. First, she maximizes lifetime utility through a decision on fertility investment. Second, after revelation of the number of children, she chooses education effort and savings so as to maximize contingent expected utility, as given by (4). A solution is determined by backward induction. Due to the properties of the probability functions and the utility function it is natural to assume interior solutions. Hence, lifetime income is always large enough to arrive at $c_{i j}>0$ in the household's optimum.

According to whether or not the fertility investment has led to births, the contingent first-order conditions for savings are

$$
\begin{aligned}
-1+R v^{\prime}\left(z_{i \mathbf{0}}\right) & =0, \\
-1+R\left[q\left(e_{i}\right) v^{\prime}\left(z_{i n}^{h}\right)+\left(1-q\left(e_{i}\right)\right) v^{\prime}\left(z_{i n}^{l}\right)\right] & =0 .
\end{aligned}
$$

The equations state that the marginal expected rate of substitution between old age consumption and working age consumption will be equal to the relative price $1 / R$. Obviously, the same consumption level in old age turns out irrespective of previous productivity for childless individuals, $z_{70}=z_{h 0}$. Furthermore, old age consumption of individuals of a given productivity type varies both with the number and type of children if and only if $\gamma>0$.

Choosing the educational investment per child is of course only relevant for individuals with children. The type-specific first-order conditions are given by

$$
-n \rho\left(\theta_{i}\right)+q^{\prime}\left(e_{i}\right)\left[v\left(z_{i n}^{h}\right)-v\left(z_{i n}^{l}\right)+\psi\left(\theta_{h}\right)-\psi\left(\theta_{l}\right)\right]=0 .
$$

In the optimum, the marginal cost associated with one additional unit of education effort in the second period, $n \rho\left(\theta_{i}\right)$, is equal to the expected marginal benefit. The latter arises through an increased probability of high productivity children according to $q^{\prime}\left(e_{i}\right)$. Parents prefer to have high productivity 
children for its own sake, as expressed by $\psi\left(\theta_{h}\right)-\psi\left(\theta_{l}\right)>0$. Moreover, their old age consumption may increase if their children's contributions have a direct impact on their pension, where the utility gain is given by $v\left(z_{i n}^{h}\right)-v\left(z_{i n}^{l}\right)$.

Finally, the first-order condition for optimal fertility investment is

$$
\begin{aligned}
& -1-p^{\prime}\left(m_{i}\right)\left[n\left[K+\rho\left(\theta_{i}\right) e_{i}\right]+s_{i n}-s_{i 0}\right]+p^{\prime}\left[q\left(e_{i}\right)\left[v\left(z_{i n}^{h}\right)+\psi\left(\theta_{h}\right)\right]\right. \\
& \left.+\left(1-q\left(e_{i}\right)\right)\left[v\left(z_{i n}^{l}\right)+\psi\left(\theta_{l}\right)\right]-\left[v\left(z_{i 0}\right)\right]\right]=0 .
\end{aligned}
$$

Investing one additional dollar in fertility directly reduces working age consumption. It increases the probability of $n$ births according to $p^{\prime}\left(m_{i}\right)$. Having: these $n$ children will be associated with direct $\operatorname{costs} n K$, and costs of education $n \rho\left(\theta_{i}\right) e_{i}$. Saving then changes from $s_{i 0}$ to $s_{i n}$. If the education effort turns out to be successful, which happens with probability $q\left(e_{i}\right)$, the household will arrive at utility from old age consumption and children as given by $v\left(z_{i n}^{h}\right)+\psi\left(\theta_{h}\right)$. The respective values for parents with less productive children and childless individuals are $v\left(z_{i n}^{l}\right)+\psi\left(\theta_{l}\right)$ and $v\left(z_{i 0}\right)$.

\section{Comparative Statics}

Comparative static results on the impacts of changes in the flat pension, the contribution-related pension, and the fertility-related pension are summarized in Lemma 1.

Lemma 1 Increasing either the lump-sum pension, $\delta$, or the contributionrelated pension, $\alpha \theta_{i}$, leads to a compensating fall in savings where all old age consumption levels, $z_{i \mathbf{0}}, z_{i n}^{h}, z_{i n}^{l}$, educational investment, $e_{i}$, and fertility investment, $m_{i}$, are unchanged. Increasing the fertility-related pension, $\beta n$, does not affect savings of childless individuals, $s_{i \mathbf{0}}$, induces a compensating fall in savings of individuals with children, $s_{i n}$, leaves educational investment per child unchanged, and increases the fertility investment level.

Proof. See Appendix A. 
Due to the specification of the quasi-linear utility function and the assumption that income suffices for having positive working age consumption, all income increases are exclusively used to raise working age consumption. A rising fertility-related pension increases the marginal benefit of a child. Hence, increasing the fertility investment level is the natural consequence.

Lemma 2 shows the consequences of varying the share of contributions that are directly collected by the respective parents.

Lemma 2 Raising the pension contingent on the children's contribution, $\gamma n \theta_{k}$, does not affect savings of childless individuals, decreases savings of individuals with children, and raises both investment in education per child and investment in fertility.

Proof. See Appendix B.

Again, rising pensions are compensated by a reduction in savings to satisfy the condition on the intertemporal distribution of consumption. As education becomes more profitable, it is not surprising that the educational effort per child is increased. At an unchanged education effort, we also have a higher marginal benefit from investment in fertility. Therefore, the fertility investment goes up.

Last, Lemma 3 demonstrates the differences in the behavior of the two types.

Lemma 3 More productive individuals save less both with and without children, and invest more in fertility and education per child.

Proof. See Appendix C.

More productive individuals receive a higher net income, face a lower price of education of their children and will have a higher contribution-related pension. Since increases in income are always used to raise working age consumption, savings decrease due to both a higher contribution-related pension and the income effect associated with the smaller price of education. A lower price of education implies that the price of a child also goes down for any 
given positive education effort. Hence, it is easily understood that productive individuals invest more in both fertility and education per child.

\section{First-best allocations}

First-best allocations are defined as follows. A first-best allocation maximizes welfare of the currently working age generation subject to taxing this generation and the next generation at the exogenous rate $\tau$. With quasilinear utility, marginal utility from working age consumption will be unity across individuals. Since redistribution will not affect welfare as long as the condition for marginal utility is met, a continuum of first-best allocations exists.

First, equalizing marginal utility across states in old age implies that

$$
v^{\prime}\left(z_{i 0}\right)=v^{\prime}\left(z_{i n}^{l}\right)=v^{\prime}\left(z_{i n}^{h}\right)=1 / R
$$

has to hold in any social optimum, where the subscript denotes the type of the individual and the number of children, and the superscript their productivity. Hence, a perfect old age consumption insurance has to exist.

Socially optimal investment in education then balances the cost of education against all benefits accruing to the parent generation:

$$
-n \rho\left(\theta_{i}\right)+q^{\prime}\left(e_{i}\right)\left[\psi\left(\theta_{h}\right)-\psi\left(\theta_{l}\right)+\tau n\left(\theta_{h}-\theta_{l}\right) / R\right]=0 .
$$

In the optimum, the type-specific cost of increasing education for the $n$ children in the family by one unit, $n \rho\left(\theta_{i}\right)$, is equal to the sum of the expected non-monetary payoff for the parents, $q^{\prime}\left(e_{i}\right)\left[\psi\left(\theta_{h}\right)-\psi\left(\theta_{l}\right)\right]$, and the present value of the expected additional transfers from these children to the public pension system, $q^{\prime}\left(e_{i}\right)\left[\tau n\left(\theta_{h}-\theta_{l}\right) / R\right]$. Since $q$ is strictly concave, the smaller price of education for more productive parents implies that these parents have to invest more into their children's human capital, $e_{h}>e_{l}$. Comparing the conditions for the two types of parents yields

$$
\frac{q^{\prime}\left(e_{h}\right)}{n \rho\left(\theta_{h}\right)}=\frac{q^{\prime}\left(e_{l}\right)}{n \rho\left(\theta_{l}\right)}
$$


In other words, the marginal impact of investing an additional dollar into education of a child has to be the same for low productivity parents and high productivity parents.

Turning to the fertility investment decision, the optimality condition is

$$
\begin{aligned}
& -\left(1+p^{\prime}\left(m_{i}\right) n\left(K+\rho\left(\theta_{i}\right) e_{i}\right)\right) \\
& +p^{\prime}\left(m_{i}\right) n \tau \frac{1}{R}\left[q\left(e_{i}\right) \theta_{h}+\left(1-q\left(e_{i}\right)\right) \theta_{l}\right] \\
& +p^{\prime}\left(m_{i}\right)\left[q\left(e_{i}\right) \psi\left(\theta_{h}\right)+\left(1-q\left(e_{i}\right)\right) \psi\left(\theta_{l}\right)\right] \\
& =0 .
\end{aligned}
$$

Increasing the fertility investment by one unit yields additional expected costs of raising and educating children of $p^{\prime}\left(m_{i}\right) n\left(K+\rho\left(\theta_{i}\right) e_{i}\right)$. The present value of the expected pension contributions of the potential children increases by $p^{\prime}\left(m_{i}\right) n \tau\left[q\left(e_{i}\right) \theta_{h}+\left(1-q\left(e_{i}\right)\right) \theta_{l}\right] / R$. In addition, the expected nonmonetary payoff to potential parents rises by $\left.p^{\prime}\left(m_{i}\right)\left[q\left(e_{i}\right) \psi\left(\theta_{h}\right)+\left(1-q\left(e_{i}\right)\right) \psi\left(\theta_{l}\right)\right]\right]$.

Note that the difference between marginal social benefits and marginal social costs of education for a given number of children must be higher for high productivity parents in the social optimum. This property would already hold if high productivity parents choose the same human capital investment as low productivity parents. The social planner deviates from imitating the low productivity parents in order to achieve an even higher difference between expected benefits and costs. This observation implies that $p^{\prime}$ is lower for high productivity individuals. Since $p$ is a strictly concave function, high productivity individuals invest more in fertility, leading to a higher expected number of children.

The outcome that productive parents have more children on average and invest more per child reflects their advantage in human capital production. This result need not hold if opportunity costs were taken into account such that, for example, lifetime labor supply has to be reduced with a higher number of children irrespective of the mother's productivity.

In a laissez-faire economy with a lump-sum pension, we have two deviations from the social optimum. As individuals neglect the positive fiscal 
externalities, they invest too little in both the quantity and the quality of human capital. If this problem is solved by assigning all contributions of a child to her mother, we will no longer have the same level of old age consumption irrespective of her children's productivity.

\section{Second-best pension schemes}

The government's problem is now to maximize aggregate expected utility

$$
W=N^{h} E U_{h}+N^{l} E U_{l}
$$

with respect to the pension parameters $\alpha, \beta, \gamma, \delta$ subject to the individual's first-order conditions for optimum savings, education effort, and fertility investment, being represented by demand functions, and the pension budget constraint

$$
\begin{aligned}
\Psi:= & \sum_{i=h, l}\left(\tau N^{i} p\left(m_{i}\right) n\left[q\left(e_{i}\right) \theta_{h}+\left[1-q\left(e_{i}\right)\right] \theta_{l}\right]\right. \\
& \left.-N^{i}\left[p\left(m_{i}\right)\left[q\left(e_{i}\right) \pi_{i n}^{h}+\left[1-q\left(e_{i}\right)\right] \pi_{i n}^{l}\right]+\left[1-p\left(m_{i}\right)\right] \pi_{i \mathbf{0}}\right]\right) \\
\geq & 0 .
\end{aligned}
$$

Hence, we focus on a linear PAYG scheme. The first-order conditions are

$$
\frac{\partial L}{\partial \phi}=\frac{\partial W}{\partial \phi}+\lambda \frac{\partial \Psi}{\partial \phi}, \quad \text { for } \phi=\alpha, \delta, \gamma, \beta
$$

where $\lambda$ is the Lagrange multiplier of the PAYG budget constraint. The envelope theorem implies that all terms vanish except for the direct impacts of parameter $\phi$ changes through the pension scheme and the repercussions in the pension budget restriction. Raising a pension parameter increases welfare through higher values of old age consumption. At the optimum, this increase will be equal to the shadow value of the resulting marginal budget deficit. The revenue side of the pension budget changes due a varying number 
and quality of contributors. Fxpenditures change directly and through the stochastic consequences of the behavioral responses in the parent generation.

For the contribution-related pension parameter $\alpha$ and the flat pension $\delta$, the first-order conditions boil down to $\lambda=1 / R$. The two parameters are to some extent indeterminate because redistribution is neutral with respect to welfare.

Using $\lambda=1 / R$, the first-order condition for the fertility-related pension parameter $\beta$ is

$$
\begin{aligned}
\frac{\partial L}{\partial \beta}= & \frac{1}{R} \sum_{i=h, l} p^{\prime}\left(m_{i}\right) \frac{\partial m_{i}}{\partial \beta} N^{i}\left[\tau n\left[q\left(e_{i}\right) \theta_{h}+\left(1-q\left(e_{i}\right)\right) \theta_{l}\right]\right. \\
& \left.-\left[q\left(e_{i}\right) \pi_{i n}^{h}+\left(1-q\left(e_{i}\right)\right) \pi_{i n}^{l}-\pi_{i \mathbf{0}}\right]\right] \\
= & 0 .
\end{aligned}
$$

With an increasing $\beta$, the positive impact on welfare through rising old age consumption levels is perfectly offset by a higher social security deficit at given fertility levels. The net impacts arise through increasing fertility. This raises both the number of future contributors and the number of individuals receiving pension components for parents. Condition (18) shows that at the second-best optimum parents of at least one productivity group $i$ will receive aggregate excess pension benefits $N^{i} p\left(m_{i}\right)\left[q\left(e_{i}\right) \pi_{i n}^{h}+\left(1-q\left(e_{i}\right)\right) \pi_{i n}^{l}-\pi_{i 0}\right]$ amounting to at least the expected total contributions of their children, $N^{i} p\left(m_{i}\right) \tau n\left[q\left(e_{i}\right) \theta_{h}+\left(1-q\left(e_{i}\right)\right) \theta_{l}\right]$. If this holds for both groups, childless individuals do not receive any benefit. Inserting the pension formulas into (18) and isolating $\beta$ yields

$$
\beta=(\tau-\gamma) \frac{\sum_{i=h, l} N^{i} p^{\prime}\left(m_{i}\right) \frac{\partial m_{i}}{\partial \beta}\left[q\left(e_{i}\right) \theta_{h}+\left(1-q\left(e_{i}\right)\right) \theta_{l}\right]}{\sum_{i=h, l} N^{i} p^{\prime}\left(m_{i}\right) \frac{\partial m_{i}}{\partial \beta}} .
$$

Hence, if $\gamma$ is equal to its maximum value, $\tau$, the fertility-related pension parameter $\beta$ must be zero. If $\gamma$ is smaller than $\tau, \beta$ will be positive. The fertility-related pension element is a substitute for children's contributions being directly assigned to their parents. 
For the pension part contingent on the own children's contributions, the first-order condition is

$$
\begin{aligned}
\frac{\partial L}{\partial \gamma}= & \sum_{i=h, l}\left\{N ^ { i } n p ( m _ { i } ) \left(q\left(e_{i}\right)\left[\theta_{h}-\theta_{l}\right]\left[v^{\prime}\left(z_{i n}^{h}\right)-(1 / R)\right]\right.\right. \\
& +\frac{1}{R} q^{\prime}\left(e_{i}\right) \frac{\partial e_{i}}{\partial \gamma}\left[\tau\left[\theta_{h}-\theta_{l}\right]-(1 / n)\left[\pi_{i n}^{h}-\pi_{i n}^{l}\right]\right] \\
& +\frac{1}{R p\left(m_{i}\right)} p^{\prime}\left(m_{i}\right) \frac{\partial m_{i}}{\partial \gamma}\left[\tau\left[q\left(e_{i}\right) \theta_{h}+\left(1-q\left(e_{i}\right)\right) \theta_{l}\right]\right. \\
& \left.\left.\left.-(1 / n)\left[q\left(e_{i}\right) \pi_{i n}^{h}+\left(1-q\left(e_{i}\right)\right) \pi_{i n}^{l}-\pi_{i 0}\right]\right]\right)\right\} \\
= & 0
\end{aligned}
$$

where $\lambda=1 / R$ and (8) have been used. Equation (20) can be interpreted as follows. First, increasing the pension contingent on own children's contributions raises welfare through more old age consumption of parents, but also implies a deficit in the pension scheme. Note that perfect consumption smoothing across all states is impossible with $\gamma>0$. As can be seen from $v^{\prime}\left(z_{i n}^{h}\right)-(1 / R)<0$ if $\gamma>0$, the net effect on welfare will be negative if this instrument is used. Second, with a rising education investment, we will have more high productivity individuals among the contributors and more pensioners with children receiving the higher benefit. Third, as fertility is also increased, both the total number of contributors and the number of individuals claiming parental benefits will rise.

Inserting the pension formulas, the last equation can be written as

$$
\begin{aligned}
\frac{\partial L}{\partial \gamma}= & \sum_{i=h, l}\left\{N ^ { i } n p ( m _ { i } ) \left(q\left(e_{i}\right)\left[\theta_{h}-\theta_{l}\right]\left[v^{\prime}\left(z_{i n}^{h}\right)-(1 / R)\right]\right.\right. \\
& +\frac{1}{R} q^{\prime}\left(e_{i}\right) \frac{\partial e_{i}}{\partial \gamma}\left[(\tau-\gamma)\left[\theta_{h}-\theta_{l}\right]\right] \\
& \left.\left.+\frac{1}{R p\left(m_{i}\right)} p^{\prime}\left(m_{i}\right) \frac{\partial m_{i}}{\partial \gamma}\left[(\tau-\gamma)\left[q\left(e_{i}\right) \theta_{h}+\left(1-q\left(e_{i}\right)\right) \theta_{l}\right]-\beta\right]\right)\right\} \\
= & 0
\end{aligned}
$$


Proposition 1 describes the two main features of second-best schemes.

Proposition 1 Any second-best linear PAYG scheme is characterized (i) by partial assignment of children's contributions to their parents (i.e. $0<\gamma<$ $\tau$ ), and (ii) by a strictly positive fertility-related component (i.e. $\beta>0$ ).

Proof. See Appendix D.

The proposition is easily understood. If parents would receive the full contribution of their children, there is no role for a purely fertility-related component. However, with such a perfect internalization, old age consumption smoothing across different states according to the children's productivity is not achieved. Utility can therefore be increased by a reduction of the pension contingent on own children's contribution and using these resources in a different fashion. Furthermore, if we do not have a full assignment of children's contributions to their parents, it always pays to introduce purely fertility-related pensions. This result turns out since the externality is still present and fertility-related pensions do not increase the old age consumption risk among parents. Last, it is not optimal to exclusively rely on fertilityrelated pensions. The obvious reason is that the positive externalities of investing in human capital is not properly addressed by such a policy.

An obvious objection against our analysis lies in the restricted set of solutions by imposing a parametric linear structure of the pension formula. As an alternative, $\pi_{i \mathbf{0}}, \pi_{i n}^{h}$ and $\pi_{i n}^{l}$ for $i=h, l$ may be taken as control variables, where a non-linear second-best pension system can be derived. We omit the calculation here since the optimum non-linear scheme turns out to be similar to the linear PAYG scheme. We obtain $\lambda=1 / R$ and $N^{h} \pi_{h \mathbf{0}}+N^{l} \pi_{l 0}=0$. If pensions cannot become negative, this condition means that childless individuals will not receive any pension. Furthermore, parents of high productivity children should receive higher pensions than parents of low productivity children (i.e. $\pi_{i n}^{h}>\pi_{i n}^{l}$ ). Finally, they should receive less than their children contribute (i.e. $\pi_{i n}^{j}<\tau \theta_{j} n$ ) provided that $\pi_{h 0}=\pi_{l 0}=0$. 


\section{Conclusion}

Incorporating the fiscal externalities of investing in the quantity and quality of human capital arising through the pension scheme requires encouraging both fertility and education. We have restricted our attention to modifications of the pension formula. In a deterministic environment, a perfect internalization would be achieved by assigning all contributions of a child to her parent. Such a policy may still be associated with underinvestment in education if parents do not take the benefits accruing to their children fully into account. Our analysis has ignored these relations between parents and their children and focuses on the impacts of uncertain investment outcomes instead. Due to the uncertainty of the investment into education, the optimum scheme requires that parents receive less than the total contributions of their children. Insurance against having less productive children is provided by a purely fertility-related component in the pension formula.

If alternative instruments are used, the purely fertility-related component of the incentive payment will typically be a family allowance, where the amount is not contingent on parental income. Replacing the contributions paid by children requires payments that depend on revealed ability of the child. An example of such a benefit is a scholarship being paid for advanced students. Since parents of high productivity will invest more per child, they will on average receive more of these benefits.

The obvious drawback of our analysis is that there is no rationale for providing insurance against having no children. This problem does not arise here, as the quasi-linear utility function ensures that expected marginal utility of consumption will not be affected by the number of children. In a more general framework, the consequences of designing such an element of insurance will probably be ambiguous. Even comparing child care costs to the expected present value of excess pension benefits for parents does not indicate the direction of income redistribution across states when the existence of children affects the marginal utility of consumption. The clear tendency however is that higher child care costs call for even stronger subsidization 
of families. On the other hand, a more generous pension scheme associated with high benefits for families may require some compensation for those who remain childless. 


\section{Appendix}

\section{A: Proof of Lemma 1}

The Jacobian of the system of equations (7)-(10) is

$$
\left[\begin{array}{cccc}
R^{2} v^{\prime \prime}\left(z_{i 0}\right) & 0 & 0 & 0 \\
0 & a_{22} & a_{23} & 0 \\
0 & a_{32} & a_{33} & 0 \\
0 & 0 & 0 & p^{\prime \prime}\left(m_{i}\right) / p^{\prime}\left(m_{i}\right)
\end{array}\right]
$$

with

$$
\begin{aligned}
& a_{22}=R^{2}\left[q\left(e_{i}\right) v^{\prime \prime}\left(z_{i n}^{h}\right)+\left(1-q\left(e_{i}\right)\right) v^{\prime \prime}\left(z_{i n}^{l}\right)\right]<0, \\
& a_{23}=a_{32}=R q^{\prime}\left(e_{i}\right)\left[v^{\prime}\left(z_{i n}^{h}\right)-v^{\prime}\left(z_{i n}^{l}\right)\right] \leq 0, \\
& a_{33}=\frac{q^{\prime \prime}\left(e_{i}\right) n \rho\left(\theta_{i}\right)}{q^{\prime}\left(e_{i}\right)}<0
\end{aligned}
$$

where (7)-(10) are already taken into account.

Ignoring the boundary case that only necessary conditions hold, the determinant of the Jacobian has to be positive in order to satisfy all sufficient second-order conditions:

$$
\Delta=R^{2} v^{\prime \prime}\left(z_{i 0}\right) \frac{p^{\prime \prime}\left(m_{i}\right)}{p^{\prime}\left(m_{i}\right)}\left[a_{22} a_{33}-a_{23} a_{32}\right]>0,
$$

which requires $a_{22} a_{33}-a_{23} a_{32}>0$.

The vector of derivatives of the equations (7)-(10) with respect to $\delta$ is

$$
\left[\begin{array}{c}
R v^{\prime \prime}\left(z_{i 0}\right) \\
a_{22} / R \\
a_{32} / R \\
0
\end{array}\right]
$$

Applying the implicit function theorem then yields

$$
\frac{\partial s_{i \mathbf{0}}}{\partial \delta}=\frac{\partial s_{i n}}{\partial \delta}=-\frac{1}{R}<0, \frac{\partial e_{i}}{\partial \delta}=\frac{\partial m_{i}}{\partial \delta}=0 .
$$


In a perfectly analogous fashion, it follows that

$$
\frac{\partial s_{i \mathbf{0}}}{\partial \alpha}=\frac{\partial s_{i n}}{\partial \alpha}=-\frac{\theta_{i}}{R}<0, \frac{\partial e_{i}}{\partial \alpha}=\frac{\partial m_{i}}{\partial \alpha}=0 .
$$

The vector of derivatives of the equations (7)-(10) with respect to $\beta$ is

$$
\left[\begin{array}{c}
0 \\
n a_{22} / R \\
n a_{32} / R \\
p^{\prime}\left(m_{i}\right) n / R
\end{array}\right]
$$

Applying the implicit function theorem then yields

$$
\frac{\partial s_{i 0}}{\partial \beta}=0, \frac{\partial s_{i n}}{\partial \beta}=-\frac{n}{R}<0, \frac{\partial e_{i}}{\partial \beta}=0, \frac{\partial m_{i}}{\partial \beta}=-\frac{\left[p^{\prime}\left(m_{i}\right)\right]^{2} n}{R p^{\prime \prime}\left(m_{i}\right)}>0
$$

\section{B: Proof of Lemma 2}

The vector of derivatives of the equations (7)-(10) with respect to $\gamma$ is

$$
\left[\begin{array}{c}
0 \\
a_{22} \frac{n}{R} \theta_{l}+\left(\theta_{h}-\theta_{l}\right) R n q\left(e_{i}\right) v^{\prime \prime}\left(z_{i n}^{h}\right) \\
a_{32} \frac{n}{R} \theta_{l}+\left(\theta_{h}-\theta_{l}\right) n q^{\prime}\left(e_{i}\right) v^{\prime}\left(z_{i n}^{h}\right) \\
p^{\prime}\left(m_{i}\right) \frac{n}{R} \theta_{l}+\left(\theta_{h}-\theta_{l}\right) p^{\prime} n q\left(e_{i}\right) v^{\prime}\left(z_{i n}^{h}\right)
\end{array}\right]
$$

Applying the implicit function theorem then yields $\partial s_{i 0} / \partial \gamma=0$,

$$
\begin{aligned}
\frac{\partial s_{i n}}{\partial \gamma} & =-\frac{b_{s \gamma}}{\left[a_{22} a_{33}-a_{23} a_{32}\right]}, \\
\frac{\partial e_{i}}{\partial \gamma} & =-\frac{b_{e \gamma}}{\left[a_{22} a_{33}-a_{23} a_{32}\right]}, \\
\frac{\partial m_{i}}{\partial \gamma} & =-\frac{p^{\prime}\left(m_{i}\right) \frac{n}{R} \theta_{l}+\left(\theta_{h}-\theta_{l}\right) p^{\prime}\left(m_{i}\right) n q\left(e_{i}\right) v^{\prime}\left(z_{i n}^{h}\right)}{p^{\prime \prime}\left(m_{i}\right) / p^{\prime}\left(m_{i}\right)}>0,
\end{aligned}
$$


with $a_{22} a_{33}-a_{23} a_{32}>0$ due to the strict concavity of the household's optimization problem, and

$$
\begin{aligned}
b_{s \gamma}= & \theta_{l} \frac{n}{R}\left[a_{22} a_{33}-a_{23} a_{32}\right]+\operatorname{Rn}\left[\theta_{h}-\theta_{l}\right]\left[q\left(e_{i}\right) v^{\prime \prime}\left(z_{i n}^{h}\right) \frac{q^{\prime \prime}\left(e_{i}\right) n \rho\left(\theta_{i}\right)}{q^{\prime}\left(e_{i}\right)}(3\right. \\
& \left.\quad-\left[q^{\prime}\left(e_{i}\right)\right]^{2} v^{\prime}\left(z_{i n}^{h}\right)\left[v^{\prime}\left(z_{i n}^{h}\right)-v^{\prime}\left(z_{i n}^{l}\right)\right]\right] \\
> & 0, \\
b_{e \gamma}= & R^{2} n q^{\prime}\left(e_{i}\right)\left[\theta_{h}-\theta_{l}\right]\left[\left[q v^{\prime \prime}\left(z_{i n}^{h}\right)+(1-q) v^{\prime \prime}\left(z_{i n}^{l}\right)\right] v^{\prime}\left(z_{i n}^{h}\right)\right. \\
& \left.-\left[v^{\prime}\left(z_{i n}^{h}\right)-v^{\prime}\left(z_{i n}^{l}\right)\right] q v^{\prime \prime}\left(z_{i n}^{h}\right)\right] \\
= & R^{2} n q^{\prime}\left(e_{i}\right)\left[\theta_{h}-\theta_{l}\right]\left[\left(1-q\left(e_{i}\right)\right) v^{\prime \prime}\left(z_{i n}^{l}\right) v^{\prime}\left(z_{i n}^{h}\right)+q\left(e_{i}\right) v^{\prime \prime}\left(z_{i n}^{h}\right) v^{\prime}\left(z_{i n}^{l}\right)\right] \\
< & 0 .
\end{aligned}
$$

\section{C: Proof of Lemma 3}

The vector of derivatives of the equations $(7)-(10)$ with respect to $\theta$ is

$$
\left[\begin{array}{c}
\alpha R v^{\prime \prime}\left(z_{0}\right) \\
\frac{\alpha}{R} a_{22} \\
-n \rho^{\prime}(\theta)+\frac{\alpha}{R} a_{32} \\
-e n \rho^{\prime}(\theta) p^{\prime}(m)
\end{array}\right]
$$

Applying the implicit function theorem then yields $\partial s_{0} / \partial \theta=-\alpha / R$,

$$
\begin{aligned}
\frac{\partial s_{n}}{\partial \theta} & =-\frac{b_{s \theta}}{\left[a_{22} a_{33}-a_{23} a_{32}\right]} \\
\frac{\partial e}{\partial \theta} & =-\frac{b_{e \theta}}{\left[a_{22} a_{33}-a_{23} a_{32}\right]} \\
\frac{\partial m}{\partial \theta} & =\frac{e n \rho^{\prime}(\theta) p^{\prime}(m)}{p^{\prime \prime}(m) / p^{\prime}(m)}>0
\end{aligned}
$$

with $a_{22} a_{33}-a_{23} a_{32}>0$ due to the strict concavity of the household's optimization problem, and 


$$
\begin{aligned}
& b_{s \theta}=\frac{\alpha}{R}\left[a_{22} a_{33}-a_{23} a_{32}\right]+a_{23} n \rho^{\prime}(\theta)>0, \\
& b_{e \theta}=-R^{2}\left[q(e) v^{\prime \prime}\left(z_{n}^{h}\right)+(1-q(e)) v^{\prime \prime}\left(z_{n}^{l}\right)\right] n \rho^{\prime}(\theta)<0 .
\end{aligned}
$$

\section{D: Proof of Proposition 1}

Note that $\gamma=\tau$ will be associated with $\beta=0$ according to (18). In this event, it follows that $\frac{\partial L}{\partial \gamma}<0$, since $v^{\prime}\left(z_{i n}^{h}\right)-(1 / R)<0$. Hence, $\gamma<\tau$ must hold for the optimum scheme.

With $\gamma<\tau$, the inequality $\frac{\partial L}{\partial \beta}>0$ holds at $\beta=0$. Therefore, the optimum scheme requires $\beta>0$.

Consider now the boundary $\gamma=0$, where $\beta$ is chosen so as to satisfy (18). Then we have $v^{\prime}\left(z_{i n}^{h}\right)-(1 / R)=0$ and, according to the Lemmas 1 and 2 , $\frac{\partial m_{i}}{\partial \gamma}=\left[\theta_{l}+\left[\theta_{h}-\theta_{l}\right] q\left(e_{i}\right)\right] \frac{\partial m_{i}}{\partial \beta}$. Taking (19) into account, we finally get

$$
\begin{aligned}
\frac{\partial L}{\partial \gamma}= & \sum_{i=h, l} N^{i} n p\left(m_{i}\right) \frac{1}{R} q^{\prime}\left(e_{i}\right) \frac{\partial e_{i}}{\partial \gamma} \tau\left[\theta_{h}-\theta_{l}\right] \\
& +\frac{\tau N^{h} N^{l} n p^{\prime}\left(m_{h}\right) p^{\prime}\left(m_{l}\right) \frac{\partial m_{h}}{\partial \beta} \frac{\partial m_{l}}{\partial \beta}\left[q\left(e_{h}\right)-q\left(e_{l}\right)\right]^{2}\left[\theta_{h}-\theta_{l}\right]^{2}}{R \sum_{i=h, l} N^{i} p^{\prime}\left(m_{i}\right) \frac{\partial m_{i}}{\partial \beta}}
\end{aligned}
$$

at $\gamma=0$. Thus, $\gamma>0$ must be a property of the optimum scheme. 


\section{References}

Abio, G., Mahieu, G., Patxot, C., 2004. On the optimality of PAYG pension systems in an endogenous fertility setting. Journal of Pension Economics and Finance 3, 35-62.

Becker, G.S., Barro, R.J., 1988. A reformulation of the economic theory of fertility. Quarterly Journal of Economics 103, 1-25.

Boldrin, M., De Nardi, M., Jones, L.E., 2005. Fertility and social security. NBER Discussion Paper No. 11146, Cambridge, MA.

Cigno, A., 1993. Intergenerational transfers without altruism. Family, market and state. European Journal of Political Economy 9, 505-518.

Cigno, A., Luporini, A., 2003. Optimal policy towards families with different amounts of social capital in the presence of asymmetric information and stochastic fertility. Paper presented at the CESifo Venice Summer Institute 2003

Cigno, A., Luporini, A., Pettini, A., 2003. Transfers to families with children as a principal-agent problem. Journal of Public Economics 87, $1165-1177$.

Cigno, A., Rosati, F.C., 1996. Jointly determined saving and fertility behaviour: theory, and estimates for Germany, Italy, UK and USA. European Economic Review 40, 1561-1589.

Cigno, A., Casolaro, L., Rosati, F.C., 2003. The impact of social security on saving and fertility in Germany. Finanzarchiv 59, 189-211.

Cremer, H., Gahvari, F., Pestieau, P., 2004a. Pensions with endogenous and stochastic fertility. CORE Discussion Paper No. 2004/67, Louvain.

Cremer, H., Gahvari, F., Pestieau, P., 2004b. Pensions with heterogeneous individuals and endogenous fertility. IDEI Working Paper No. 313, University of Toulouse. 
Fenge, R., Meier, V., 2004. Are family allowances and fertility-related pensions Siamese twins? CESifo Working Paper No. 1157, Munich.

Fenge, R., Meier, V., 2005. Pensions and fertility incentives. Canadian Journal of Economics 38, 28-48.

Kolmar, M., 1997. Intergenerational redistribution in a small open economy with endogenous fertility. Journal of Population Economics 10, 335356.

Kolmar, M., 2001. Optimal intergenerational redistribution in a two-country model with endogenous fertility. Public Choice 106, 23-51.

Peters, W., 1995. Public pensions, family allowances and endogenous demographic change. Journal of Population Economics 8, 161-183.

Sinn, H.-W., 2001. The value of children and immigrants in a pay-as-yougo pension system: a proposal for a transition to a funded system. ifo Studien 47, 77-94.

Sinn, H.-W., 2004. The pay-as-you-go pension system as a fertility insurance and enforcement device, Journal of Public Economics 88, 1335-1357.

van Groezen, B., Leers, T., Meijdam, L., 2003. Social security and endogenous fertility: pensions and child allowances as Siamese twins. Journal of Public Economics 87, 233-251.

van Groezen, B., Meijdam, L. 2004. Growing old and staying young: Population policy in an ageing closed economy. Utrecht School of Economics Discussion Paper No. 04-28, Utrecht.

Wigger, B.U., 1999. Pay-as-you-go financed public pensions in a model of endogenous growth and fertility. Journal of Population Economics 12, $625-640$. 
Woessmann, L., 2004. How equal are educational opportunities? Family background and student achievement in Europe and the US. CESifo Working Paper No. 1162, Munich.

Zhang, Jie, 1995. Social security and endogenous growth. Journal of Public Economics 58, 185-213. 


\section{CESifo Working Paper Series}

(for full list see www.cesifo-group.de)

1457 Margarita Katsimi and Thomas Moutos, Inequality and Relative Reliance on Tariffs: Theory and Evidence, April 2005

1458 Monika Bütler, Olivia Huguenin and Federica Teppa, Why Forcing People to Save for Retirement may Backfire, April 2005

1459 Jos Jansen, The Effects of Disclosure Regulation of an Innovative Firm, April 2005

1460 Helge Bennmarker, Kenneth Carling and Bertil Holmlund, Do Benefit Hikes Damage Job Finding? Evidence from Swedish Unemployment Insurance Reforms, May 2005

1461 Steffen Huck, Kai A. Konrad and Wieland Müller, Merger without Cost Advantages, May 2005

1462 Louis Eeckhoudt and Harris Schlesinger, Putting Risk in its Proper Place, May 2005

1463 Hui Huang, John Whalley and Shunming Zhang, Trade Liberalization in a Joint Spatial Inter-Temporal Trade Model, May 2005

1464 Mikael Priks, Optimal Rent Extraction in Pre-Industrial England and France - Default Risk and Monitoring Costs, May 2005

1465 François Ortalo-Magné and Sven Rady, Heterogeneity within Communities: A Stochastic Model with Tenure Choice, May 2005

1466 Jukka Pirttilä and Sanna Tenhunen, Pawns and Queens Revisited: Public Provision of Private Goods when Individuals make Mistakes, May 2005

1467 Ernst Fehr, Susanne Kremhelmer and Klaus M. Schmidt, Fairness and the Optimal Allocation of Ownership Rights, May 2005

1468 Bruno S. Frey, Knight Fever - Towards an Economics of Awards, May 2005

1469 Torberg Falch and Marte Rønning, The Influence of Student Achievement on Teacher Turnover, May 2005

1470 John Komlos and Peter Salamon, The Poverty of Growth with Interdependent Utility Functions, May 2005

1471 Hui Huang, Yi Wang, Yiming Wang, John Whalley and Shunming Zhang, A Trade Model with an Optimal Exchange Rate Motivated by Current Discussion of a Chinese Renminbi Float, May 2005

1472 Helge Holden, Lars Holden and Steinar Holden, Contract Adjustment under Uncertainty, May 2005 
1473 Kai A. Konrad, Silent Interests and All-Pay Auctions, May 2005

1474 Ingo Vogelsang, Electricity Transmission Pricing and Performance-Based Regulation, May 2005

1475 Spiros Bougheas and Raymond Riezman, Trade and the Distribution of Human Capital, June 2005

1476 Vesa Kanniainen, Seppo Kari and Jouko Ylä-Liedenpohja, The Start-Up and Growth Stages in Enterprise Formation: The "New View" of Dividend Taxation Reconsidered, June 2005

1477 M. Hashem Pesaran, L. Vanessa Smith and Ron P. Smith, What if the UK had Joined the Euro in 1999? An Empirical Evaluation Using a Global VAR, June 2005

1478 Chang Woon Nam and Doina Maria Radulescu, Effects of Corporate Tax Reforms on SMEs' Investment Decisions under the Particular Consideration of Inflation, June 2005

1479 Panos Hatzipanayotou, Sajal Lahiri and Michael S. Michael, Globalization, CrossBorder Pollution and Welfare, June 2005

1480 John Whalley, Pitfalls in the Use of Ad valorem Equivalent Representations of the Trade Impacts of Domestic Policies, June 2005

1481 Edward B. Barbier and Michael Rauscher, Trade and Development in a Labor Surplus Economy, June 2005

1482 Harrie A. A. Verbon and Cees A. Withagen, Tradable Emission Permits in a Federal System, June 2005

1483 Hendrik Hakenes and Andreas Irmen, On the Long-Run Evolution of Technological Knowledge, June 2005

1484 Nicolas Schmitt and Antoine Soubeyran, A Simple Model of Brain Circulation, June 2005

1485 Carsten Hefeker, Uncertainty, Wage Setting and Decision Making in a Monetary Union, June 2005

1486 Ondřej Schneider and Jan Zápal, Fiscal Policy in New EU Member States - Go East, Prudent Man!, June 2005

1487 Christian Schultz, Virtual Capacity and Competition, June 2005

1488 Yvan Lengwiler and Elmar Wolfstetter, Bid Rigging - An Analysis of Corruption in Auctions, June 2005

1489 Johannes Becker and Clemens Fuest, Does Germany Collect Revenue from Taxing Capital Income?, June 2005 
1490 Axel Dreher and Panu Poutvaara, Student Flows and Migration: An Empirical Analysis, June 2005

1491 Bernd Huber and Marco Runkel, Interregional Redistribution and Budget Institutions under Asymmetric Information, June 2005

1492 Guido Tabellini, Culture and Institutions: Economic Development in the Regions of Europe, July 2005

1493 Kurt R. Brekke and Michael Kuhn, Direct to Consumer Advertising in Pharmaceutical Markets, July 2005

1494 Martín Gonzalez-Eiras and Dirk Niepelt, Sustaining Social Security, July 2005

1495 Alfons J. Weichenrieder, (Why) Do we need Corporate Taxation?, July 2005

1496 Paolo M. Panteghini, S-Based Taxation under Default Risk, July 2005

1497 Panos Hatzipanayotou and Michael S. Michael, Migration, Tied Foreign Aid and the Welfare State, July 2005

1498 Agata Antkiewicz and John Whalley, BRICSAM and the Non-WTO, July 2005

1499 Petr Hedbávný, Ondřej Schneider and Jan Zápal, A Fiscal Rule that has Teeth: A Suggestion for a 'Fiscal Sustainability Council' underpinned by the Financial Markets, July 2005

1500 J. Atsu Amegashie and Marco Runkel, Sabotaging Potential Rivals, July 2005

1501 Heikki Oksanen, Actuarial Neutrality across Generations Applied to Public Pensions under Population Ageing: Effects on Government Finances and National Saving, July 2005

1502 Xenia Matschke, Costly Revenue-Raising and the Case for Favoring Import-Competing Industries, July 2005

1503 Horst Raff and Nicolas Schmitt, Why Parallel Trade may Raise Producers Profits, July 2005

1504 Alberto Bisin and Piero Gottardi, Efficient Competitive Equilibria with Adverse Selection, July 2005

1505 Peter A. Zadrozny, Necessary and Sufficient Restrictions for Existence of a Unique Fourth Moment of a Univariate GARCH(p,q) Process, July 2005

1506 Rainer Niemann and Corinna Treisch, Group Taxation, Asymmetric Taxation and Cross-Border Investment Incentives in Austria, July 2005

1507 Thomas Christiaans, Thomas Eichner and Ruediger Pethig, Optimal Pest Control in Agriculture, July 2005 
1508 Biswa N. Bhattacharyay and Prabir De, Promotion of Trade and Investments between China and India: The Case of Southwest China and East and Northeast India, July 2005

1509 Jean Hindriks and Ben Lockwood, Decentralization and Electoral Accountability: Incentives, Separation, and Voter Welfare, July 2005

1510 Michelle R. Garfinkel, Stergios Skaperdas and Constantinos Syropoulos, Globalization and Domestic Conflict, July 2005

1511 Jesús Crespo-Cuaresma, Balázs Égert and Ronald MacDonald, Non-Linear Exchange Rate Dynamics in Target Zones: A Bumpy Road towards a Honeymoon - Some Evidence from the ERM, ERM2 and Selected New EU Member States, July 2005

1512 David S. Evans and Michael Salinger, Curing Sinus Headaches and Tying Law: An Empirical Analysis of Bundling Decongestants and Pain Relievers, August 2005

1513 Christian Keuschnigg and Martin D. Dietz, A Growth Oriented Dual Income Tax, July 2005

1514 Fahad Khalil, David Martimort and Bruno Parigi, Monitoring a Common Agent: Implications for Financial Contracting, August 2005

1515 Volker Grossmann and Panu Poutvaara, Pareto-Improving Bequest Taxation, August 2005

1516 Lars P. Feld and Emmanuelle Reulier, Strategic Tax Competition in Switzerland: Evidence from a Panel of the Swiss Cantons, August 2005

1517 Kira Boerner and Silke Uebelmesser, Migration and the Welfare State: The Economic Power of the Non-Voter?, August 2005

1518 Gabriela Schütz, Heinrich W. Ursprung and Ludger Wößmann, Education Policy and Equality of Opportunity, August 2005

1519 David S. Evans and Michael A. Salinger, Curing Sinus Headaches and Tying Law: An Empirical Analysis of Bundling Decongestants and Pain Relievers, August 2005

1520 Michel Beine, Paul De Grauwe and Marianna Grimaldi, The Impact of FX Central Bank Intervention in a Noise Trading Framework, August 2005

1521 Volker Meier and Matthias Wrede, Pension, Fertility, and Education, August 2005 